\title{
Synaptic Basis for Whisker Deprivation-Induced Synaptic Depression in Rat Somatosensory Cortex
}

\author{
Kevin J. Bender, ${ }^{1 *}$ Cara B. Allen, ${ }^{2 *}$ Vanessa A. Bender, ${ }^{2}$ and Daniel E. Feldman ${ }^{1,2}$ \\ ${ }^{1}$ Division of Biological Sciences and ${ }^{2}$ Neuroscience Program, University of California San Diego, La Jolla, California 92093-0357
}

\begin{abstract}
Whisker deprivation weakens excitatory layer 4 (L4) inputs to L2/3 pyramidal cells in rat primary somatosensory (S1) cortex, which is likely to contribute to whisker map plasticity. This weakening has been proposed to represent long-term depression (LTD) induced by sensory deprivation in vivo. Here, we studied the synaptic expression mechanisms for deprivation-induced weakening of L4-L2/3 inputs and assessed its similarity to LTD, which is known to be expressed presynaptically at L4-L2/3 synapses. Whisker deprivation increased the paired pulse ratio at L4-L2/3 synapses and slowed the use-dependent block of NMDA receptor currents by MK-801 [(5S,10R)- $(+)-5-$ methyl-10,11-dihydro-5H-dibenzo[a,d]cyclohepten-5,10-imine maleate], indicating that deprivation reduced transmitter release probability at these synapses. In contrast, deprivation did not alter either miniature EPSC amplitude in L2/3 neurons or the amplitude of quantal L4-L2/3 synaptic responses measured in strontium, indicating that postsynaptic responsiveness was unchanged. In young postnatal day 12 (P12) rats, at least $4 \mathrm{~d}$ of deprivation were required to significantly weaken L4-L2/3 synapses. Similar weakening occurred when deprivation began at older ages (P20), when synapses are mostly mature, indicating that weakening is unlikely to represent a failure of synaptic maturation but instead represents a reduction in the strength of existing synapses. Thus, whisker deprivation weakens L4-L2/3 synapses by decreasing presynaptic function, similar to known LTD mechanisms at this synapse.
\end{abstract}

Key words: experience-dependent plasticity; barrel; map plasticity; LTD; release probability; short-term plasticity

\section{Introduction}

In Hebbian sensory map plasticity, behaviorally relevant stimuli expand their representation within sensory maps, whereas less relevant stimuli lose representation. Such plasticity acts to increase cortical processing capacity for relevant inputs and to drive learned improvements in sensory perceptual ability (LeVay et al., 1980; Buonomano and Merzenich, 1998; Gilbert, 1998; Dinse et al., 2003; Yao and Dan, 2005). The cellular mechanisms for Hebbian map plasticity are just beginning to be understood (Feldman and Brecht, 2005; Hensch, 2005).

A central unanswered question is whether map plasticity involves activity-dependent changes in synapse strength, including long-term potentiation (LTP) and long-term depression (LTD). We address this question by studying the loss of cortical responsiveness to deprived sensory inputs. Sensory deprivation causes measurable weakening of specific intracortical synaptic connections (Finnerty et al., 1999; Allen et al., 2003; Shepherd et al., 2003) that has similar activity dependence and biochemical characteristics as LTD (Rittenhouse et al., 1999; Heynen et al., 2003) and occludes subsequent LTD (Allen et al., 2003; Heynen et al., 2003), suggesting that it represents LTD induced in vivo. How-

Received Jan. 13, 2006; revised March 6, 2006; accepted March 7, 2006.

This work was supported by National Institutes of Health Grant R01 NS046652 and the McKnight Endowment Fund for Neuroscience. We thank J. Isaacson and M. Scanziani for helpful technical comments and P. Drew and D. Matthews for critically reading this manuscript.

${ }^{*}$ K.J.B. and C.B.A. contributed equally to this work.

Correspondence should be addressed to Kevin J. Bender, Division of Biology, University of California San Diego, 3228 Pacific Hall, 0357, 9500 Gilman Drive, La Jolla, CA 92093-0357. E-mail: kbender@ucsd.edu.

DOl:10.1523/JNEUROSCI.0175-06.2006

Copyright $\odot 2006$ Society for Neuroscience $\quad$ 0270-6474/06/264155-11\$15.00/0 ever, treatments that block specific forms of LTD have had only mixed success in disrupting map plasticity (Hensch and Stryker, 1996; Roberts et al., 1998; Renger et al., 2002; Fischer et al., 2004; Yang et al., 2005). Therefore, whether LTD is causally involved in map plasticity remains unclear.

We studied deprivation-induced synaptic weakening in rat primary somatosensory cortex (S1) to determine whether this weakening is consistent with LTD. S1 exhibits robust Hebbian map plasticity (Fox, 2002; Feldman and Brecht, 2005). Facial whiskers are represented in $\mathrm{S} 1$ by cell clusters in layer 4 (L4) called barrels that are isomorphic with the facial whisker array. L4 neurons project to neurons in layer 2/3 (L2/3) within the same cortical column, termed a barrel column. The L4-L2/3 projection drives strong responses in L2/3 to deflection of the whisker corresponding to that column, termed the principal whisker (Armstrong-James et al., 1992). When whiskers are deprived by trimming or plucking in adolescent rats [postnatal day 7 (P7) to P60], L2/3 neurons in deprived barrel columns lose responsiveness to their deprived principal whisker, whereas L4 neuronal responses are unaffected. This loss of principal whisker responses has been proposed to reflect LTD at L4-L2/3 synapses (Glazewski and Fox, 1996; Fox, 2002). Supporting this hypothesis, whisker deprivation reduces synaptic responses in L2/3 pyramidal cells to L4 stimulation, measured in ex vivo S1 slices, and this weakening occludes LTD (Allen et al., 2003; Shepherd et al., 2003).

Here, we studied the expression mechanisms of deprivationinduced weakening at L4-L2/3 synapses and assessed its similarity to LTD. Deprivation (from P12) increased paired pulse ratio (PPR) and slowed use-dependent blockade of NMDA receptor (NMDAR) currents by $(5 S, 10 R)-(+)-5$-methyl-10,11-dihydro- 
5H-dibenzo[a,d]cyclohepten-5,10-imine maleate (MK-801), indicating that deprivation reduced the probability of presynaptic glutamate release. Deprivation did not alter postsynaptic function. Deprivation-induced synaptic weakening thus resembled LTD, which is expressed presynaptically at this synapse (Bender et al., 2006). Deprivation weakened synapses similarly in more mature rats, suggesting that deprivation, like LTD, acts to weaken existing synapses rather than to prevent synaptic maturation.

\section{Materials and Methods}

Whisker deprivation. All procedures were approved by the University of California San Diego Institutional Animal Care and Use Committee. Every $2 \mathrm{~d}, \mathrm{D}$-row $(1-6)$ and $\gamma$ whiskers were plucked from the right side of Long-Evans rats under isoflurane anesthesia $\left(3 \%\right.$ in $\left.2 \mathrm{~L} / \mathrm{min} \mathrm{O}_{2}\right)$. Sham-plucked littermates were anesthetized and handled identically, but whiskers were not plucked.

Slice preparation. Rats were anesthetized with isoflurane and decapitated, and the brain was removed in either chilled normal Ringer's solution (for P15-P22 animals) (in mM: $119 \mathrm{NaCl}, 2.5 \mathrm{KCl}, 1.3 \mathrm{MgSO}_{4}, 1$ $\mathrm{NaH}_{2} \mathrm{PO}_{4}, 26.3 \mathrm{NaHCO}_{3}, 11 \mathrm{D}-(+)$-glucose, and $2.5 \mathrm{CaCl}_{2}$, bubbled with $95 \% \mathrm{O}_{2} / 5 \% \mathrm{CO}_{2}, \mathrm{pH} 7.4$ ) or low-sodium, low-calcium solution (for P23-P26 animals) (in mm: 250 sucrose, $2.5 \mathrm{KCl}, 4 \mathrm{MgSO}_{4}, 1 \mathrm{NaH}_{2} \mathrm{PO}_{4}$, 15 HEPES, $11 \mathrm{D}-(+)$-glucose, and $\left.0.1 \mathrm{CaCl}_{2}\right)$. "Across row" $\mathrm{S} 1$ slices $(400$ $\mu \mathrm{m})$ containing one barrel column from each whisker row (A-E) were cut from the left hemisphere $50^{\circ}$ from the midsagittal plane on a vibrating microtome (Finnerty et al., 1999; Allen et al., 2003). Slices were incubated in normal Ringer's solution for $30 \mathrm{~min}$ at $30^{\circ} \mathrm{C}$ and then at room temperature for $0.5-6 \mathrm{~h}$ before recording.

Electrophysiology. Recordings were made at room temperature (22$24^{\circ} \mathrm{C}$ ). Whisker barrels were visualized with transmitted light (Finnerty et al., 1999; Allen et al., 2003). To study presumptive L4-L2/3 synapses, a bipolar stimulating electrode (FHC, Bowdoinham, ME) was placed in the geometric center of a L4 barrel, $200 \mu \mathrm{m}$ below the cut surface of the slice, and whole-cell recordings were made from L2/3 pyramidal cells above the center of the stimulated barrel, $\sim 300 \mu \mathrm{m}$ below the L1-pia border (see Fig. $1 B$ ). Pyramidal cells were visualized with infrared differential interference contrast optics and selected for recording if they had clear pyramidal somata and regular spiking responses to $500 \mathrm{~ms}$ current injection (Connors and Gutnick, 1990). In a previous study, histological confirmation of pyramidal cell morphology was obtained in all $(n=50)$ L2/3 cells identified with these criteria (Feldman, 2000). Bicuculline methiodide (BMI) was applied focally via a pipette ( $5 \mathrm{~mm} \mathrm{BMI;} 5 \mu \mathrm{m}$ tip internal diameter, located $<100 \mu \mathrm{m}$ from recorded cell) to block local $\mathrm{GABA}_{\mathrm{A}}$ receptors and isolate excitatory synaptic inputs (CastroAlamancos et al., 1995; Feldman, 2000). All drugs were obtained from Tocris Cookson (Ellisville, MO).

Recordings were made with 3-4 M $\Omega$ pipettes and Axoclamp-2B, Axopatch 200B, or Multiclamp 700B amplifiers (Molecular Devices, Sunnyvale, $\mathrm{CA}$ ). For current-clamp recordings, the internal solution contained the following (in mM): $116 \mathrm{~K}$-gluconate, $6 \mathrm{KCl}, 2 \mathrm{NaCl}, 20 \mathrm{HEPES}, 0.5$ EGTA, 4 MgATP, $0.3 \mathrm{NaGTP}, 10$ phosphocreatine, pH 7.20-7.25. Input $\left(R_{\text {in }}\right)$ and series resistance $\left(R_{\mathrm{s}}\right)$ were monitored continuously with small hyperpolarizing pulses, and $R_{\mathrm{s}}$ was compensated by bridge balance. Experiments were discarded if initial $R_{\mathrm{s}}>30 \mathrm{M} \Omega$, membrane potential $\left(V_{\mathrm{m}}\right)>-75 \mathrm{mV}$, or if $V_{\mathrm{m}}$ changed $>20 \%$ during recording.

For voltage-clamp recordings, the internal contained the following (in mM): 118 D-gluconic acid, $118 \mathrm{CsOH}, 20$ HEPES, 0.4 EGTA, $2.8 \mathrm{NaCl}, 5$ tetraethylammonium-Cl, $4 \mathrm{MgATP}, 0.3 \mathrm{NaGTP}, 10$ phosphocreatine, $\mathrm{pH} 7.20-7.25$. $R_{\text {in }}$ and $R_{\mathrm{s}}$ were monitored in each sweep of the experiment or at the beginning and end of recordings for miniature EPSC (mEPSC) experiments. $R_{\mathrm{s}}$ was not compensated. Experiments were discarded if initial $V_{\mathrm{m}}>-75 \mathrm{mV}, R_{\mathrm{s}}>25 \mathrm{M} \Omega$ or $R_{\mathrm{in}}<100 \mathrm{M} \Omega$, or if $R_{\mathrm{s}}$ or $R_{\text {in }}$ changed by $20 \%$ during recording. All $V_{\mathrm{m}}$ values were adjusted for the measured liquid junction potential for the specific solutions $(10-11$ $\mathrm{mV})$.

Input-output curve measurements. Recordings were made in high divalent Ringer's solution (in mM: $116 \mathrm{NaCl}, 2.5 \mathrm{KCl}, 4 \mathrm{MgSO}_{4} \cdot 7 \mathrm{H}_{2} \mathrm{O}, 1$ $\mathrm{NaH}_{2} \mathrm{PO}_{4} \cdot \mathrm{H}_{2} \mathrm{O}, 26.2 \mathrm{NaHCO}_{3}, 8 \mathrm{D}-(+)$-glucose, $4 \mathrm{CaCl}_{2}$, bubbled with
$95 \% \mathrm{O}_{2} / 5 \% \mathrm{CO}_{2}$ ) to suppress polysynaptic responses (Allen et al., 2003). Input-output curves were measured in current clamp for multiple cells in each deprived (D) or spared (non-D; usually B) column. For each cell, stimulation threshold was identified as the lowest stimulus intensity required to reliably evoke EPSPs in five consecutive sweeps and was confirmed by verification of failures at 0.95 times threshold. Stimulation was then increased in $10 \%$ increments to 1.5 times threshold. Input-output curves were constructed from the amplitude of the short-latency component of the EPSP at each stimulus intensity (Allen et al., 2003). To offset interslice variability in overall response amplitude, input-output curves for all cells in a slice were normalized to the mean EPSP amplitude at 1.5 times threshold for cells in the non-D column of that slice.

Paired-pulse measurements. Paired stimuli with interstimulus intervals (ISIs) of 12, 20, 40, and $80 \mathrm{~ms}$ were delivered every $25 \mathrm{~s}$ (six to eight sweeps each) while recording in voltage clamp (holding potential, -70 $\mathrm{mV}$ ) in normal Ringer's solution. AMPA receptor-mediated currents were isolated with D-(-)-2-amino-5-phosphonopentanoic acid (D-AP5) $(50 \mu \mathrm{M})$ and focal BMI. PPR was defined as the mean amplitude of the second EPSC to the first. When the second pulse overlapped with the decay of the first, the tail of the first EPSC was subtracted to obtain an accurate amplitude for the second EPSC. For low-calcium experiments, $\mathrm{CaCl}_{2}$ was reduced to $1.25 \mathrm{~mm}$ and $\mathrm{MgCl}_{2}$ was raised to $2.5 \mathrm{~mm}$ to maintain total divalent ion concentration, and slices were incubated in lowcalcium Ringer's solution at least $0.5 \mathrm{~h}$ before recording.

MK-801 experiments. NMDA currents were isolated in voltage-clamp recordings by bath application of 6,7-dinitroquinoxaline-2,3-dione (DNQX) $(10 \mu \mathrm{M})$ and either picrotoxin $(100 \mu \mathrm{M})$ or focal BMI. Recordings were made in normal Ringer's solution. EPSCs were elicited every $15 \mathrm{~s}$. Following a stable baseline at $+40 \mathrm{mV}$, stimulation was paused and neurons were voltage clamped at $-70 \mathrm{mV}$ while $5 \mu \mathrm{M}$ MK-801 was added to the perfusate. After a $10 \mathrm{~min}$ equilibration period, the holding potential was returned to $+40 \mathrm{mV}$, stimulation was resumed, and progressive decay of EPSC amplitude with continued stimulation was measured. Internal solution included $5 \mathrm{~mm}$ BAPTA to prevent induction of LTP at $+40 \mathrm{mV}$. EPSC amplitude was normalized for each cell to the first EPSC in MK-801. Progressive blockade of EPSCs was fit to a double exponential function in Igor Pro (Wavemetrics, Portland, OR). Decay kinetics of NMDA-EPSCs was calculated from means of 20 sweeps.

Miniature EPSCs. AMPA-mediated mEPSCs were isolated by tetrodotoxin $(0.5 \mu \mathrm{M}), \mathrm{D}-\mathrm{AP} 5(50 \mu \mathrm{M})$, and picrotoxin $(100 \mu \mathrm{M})$. Cells were voltage clamped at $-70 \mathrm{mV}$. Continuous recordings were made using pClamp software (Molecular Devices) and analyzed with MiniAnalysis software (Synaptosoft, Decatur, GA). Automated detection of mEPSCs (criteria: amplitude, $\geq 4.5 \mathrm{pA} ; 10-90 \%$ rise time, $<2 \mathrm{~ms}$ ) was verified by visual inspection. $706 \pm 70 \mathrm{mEPSCs}$ were analyzed in each cell (range, $380-1305)$. Root mean square noise, measured between identified mEPSCs, was $1.90 \pm 0.04 \mathrm{pA}(n=12$ cells $)$.

Evoked EPSCs in strontium. AMPA receptor-mediated currents were isolated in voltage clamp (holding potential: $-70 \mathrm{mV}$ ) using D-AP5 (50 $\mu \mathrm{M})$ and focal BMI. In each slice, EPSCs $(\sim 100 \mathrm{pA})$ were first elicited in high divalent Ringer's solution. $\mathrm{CaCl}_{2}$ was then replaced by equimolar $(4$ $\mathrm{mm}) \mathrm{SrCl}_{2}$, which caused the initial, synchronous EPSC to decrease to $\sim 20-40 \mathrm{pA}$, and miniature, asynchronous EPSCs [EPSCs in strontium (SrEPSC)] to appear. Measurements were made after 20-30 min of $\mathrm{Sr}^{2+}$ perfusion when asynchronous transmission had stabilized. Stimulation intensity was maintained at initial levels for subsequent recordings in the same slice. SrEPSCs occurring 40-380 ms after onset of the residual evoked EPSC were analyzed in the same manner as mEPSCs, using identical selection criteria. This analysis window was chosen to minimize contamination by the residual evoked EPSC and by spontaneous mEPSCs, which predominate at long intervals after stimulation. $440 \pm 48$ events of mEPSCs were analyzed in each cell (range, 185-1106). Root mean square noise, measured $>500 \mathrm{~ms}$ after stimulation (after SrEPSCs had mostly subsided), was $1.95 \pm 0.05 \mathrm{pA}(n=29$ cells $)$.

Statistics. All values are expressed as mean \pm SE (SEM). The criterion for significance was $\alpha<0.05$ in all tests. 

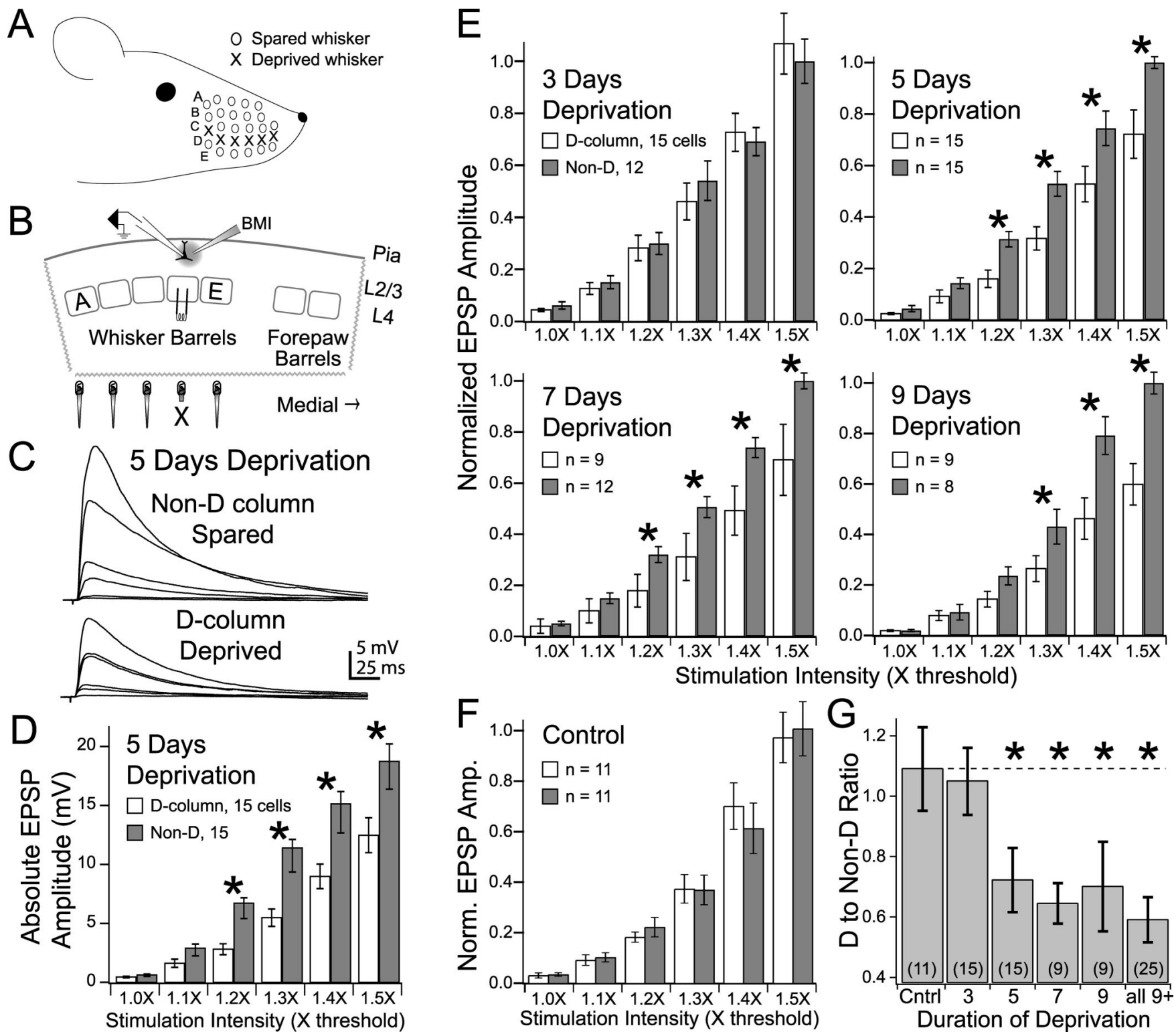

Figure 1. Time course for deprivation-induced depression of L4-L2/3 synapses. $\boldsymbol{A}$, Arrangement of large whiskers on rat snout. X, Deprived whiskers. $\boldsymbol{B}$, Schematic of slice preparation. Barrel columns from whisker rows $A$ and $E$ are labeled. Sites of stimulation, recording, and focal bicuculline (BMI) are shown. C, Representative families of EPSPs at L4-L2/3 synapses recorded in response to increasing L4 stimulation intensity (1-1.5 $\times$ threshold). Top, Spared column. Bottom, Deprived column of the same slice ( $5 \mathrm{~d}$ of deprivation from P12). $D$, Input- output curve for EPSP amplitude after $5 \mathrm{~d}$ of whisker deprivation. $\boldsymbol{E}$, Normalized input- output curves after 3, 5, 7, and $9 \mathrm{~d}$ of whisker deprivation. Data are normalized to mean EPSP amplitude for cells in spared column at $1.5 \times$ threshold. Asterisks indicate deprived columns significantly different from spared columns. $\boldsymbol{F}$, Identical data from control, nondeprived rats (Allen et al., 2003). $\mathbf{G}$, Time course of deprivation-induced depression of input- output curves, measured by the D:Non-D EPSP ratio (see Results). "Control" and "all $9+$ " incorporate data from the study by Allen et al. (2003). Numbers in parentheses are cells in the D column. Error bars are SEM.

\section{Results}

To study the synaptic mechanisms of deprivation-induced weakening of the L4-L2/3 projection, we made whole-cell recordings from L2/3 pyramidal neurons in acute brain slices $(400 \mu \mathrm{m})$ prepared from D-row whisker-deprived and sham-deprived rats (Fig. 1A). Slices were cut at an oblique angle, so that each slice contained one barrel from each of the five rows (A-E) (Finnerty et al., 1999) (see Materials and Methods). Barrels were visualized via transillumination and used to target recordings to deprived and spared barrel columns (Allen et al., 2003). Presumptive L4-L2/3 synapses were studied using extracellular stimulation in an L4 barrel and whole-cell recording from radially aligned L2/3 pyramidal cells in the same barrel column. BMI was applied focally via a nearby pipette to block $\mathrm{GABA}_{\mathrm{A}}$ receptor-mediated inhibition and isolate excitatory inputs (Allen et al., 2003) (Fig. 1B).

Time course for deprivation-induced depression

We showed previously that plucking the $\mathrm{D}$ row of whiskers for $\geq 9 \mathrm{~d}$, beginning at P12, weakens L4-L2/3 inputs in deprived (D) columns, measured by input-output curves of L4-evoked EPSPs (Allen et al., 2003). To determine the time course for deprivationinduced depression of these inputs, we performed unilateral D-row whisker deprivation for 3, 5, 7, and $9 \mathrm{~d}$ (beginning at P12) and then prepared S1 slices [preliminary results reported by Allen et al. (2003)]. Input-output curves were measured in multiple (mean, 2.1; range, 1-3) cells in the D column and one non-D 
column (usually the B column) of each slice (see Materials and Methods). As expected, deprivation reduced the absolute amplitude of input-output curves in the deprived (D) column, relative to spared (non-D) columns (shown for $5 \mathrm{~d}$ deprivation in Fig. $1 C, D)$. Stimulation intensities were not different between deprived and spared columns, indicating that comparable levels of stimulation elicited weaker EPSPs in deprived versus spared columns (supplemental Table 1, available at www.jneurosci.org as supplemental material).

To better distinguish deprivation-induced changes in inputoutput curves given the slice-to-slice variance in overall EPSP amplitude, input-output curves for all cells in each slice were normalized to the mean EPSP amplitude at 1.5 times threshold $(X)$ for all cells in the spared column of that slice. Three days of whisker deprivation did not depress normalized input-output curves in deprived columns, relative to spared columns in the same slices (Fig. $1 E$ ) $[n=15$ cells in deprived columns and 12 in spared columns, seven slices, four rats; two-way ANOVA (factors, stimulation intensity and column identity), $p=0.9$ ]. After $5 \mathrm{~d}$, significant depression was observed in deprived columns, relative to spared columns (Fig. $1 E)(n=15$ cells in deprived and 15 cells in spared columns, seven slices, five rats; ANOVA, $p<$ 0.05 ; Fisher's PLSD, $p<0.02$ at $1.2-1.5 \times)$. Similar depression was observed after $7 \mathrm{~d}$ of deprivation $(n=9$ cells in deprived columns and 12 cells in spared columns, six slices, four rats; ANOVA, $p<0.0001$; Fisher's PLSD, $p<0.01$ at $1.2-1.5 \times)$ and $9 \mathrm{~d}$ of deprivation $(n=9$ cells in deprived columns and 8 cells in spared columns, four slices, three rats; ANOVA, $p<0.001$; Fisher's PLSD, $p<0.03$ at $1.3-1.5 \times)$.

To quantify the time course of depression, we created a scalar index representing the magnitude of input-output curve depression for each cell in a deprived (D) column, relative to the spared (non-D) column of the same slice. This index, termed the D:Non-D EPSP ratio, was calculated for each D column cell as: $\left(D_{1.3} / N_{1.3}+D_{1.4} / N_{1.4}+D_{1.5} / N_{1.5}\right) / 3$, where $D_{1 . \mathrm{X}}=$ input-output curve amplitude (non-normalized, at 1.X times threshold stimulation intensity) for the $\mathrm{D}$ column cell, and $N_{1 . \mathrm{X}}=$ average input-output curve amplitude (at 1.X times threshold) for all non-D column cells in the same slice. For comparison, we also calculated the ratio from control rats from a previous study [data from Allen et al. (2003); $n=11 \mathrm{D}$ column cells, 11 non-D column cells, six slices, five rats; $21-25 \mathrm{~d}$ of age] (Fig. $1 F$ ). The D:Non-D EPSP ratio in control rats was $1.09 \pm 0.14$, indicating that $\mathrm{D}$ column EPSP amplitudes were slightly larger than non-D row amplitudes. Three days of deprivation did not depress the D:Non-D EPSP ratio (Fig. 1G). However, 5, 7, and $9 \mathrm{~d}$ of deprivation significantly reduced the D:Non-D EPSP ratio $(p<0.01$, ANOVA; $p<0.05$ for 5, 7, and 9 d, Fisher's PLSD). No correlation was found between D:Non-D EPSP ratio and deprivation duration for $\geq 5 \mathrm{~d}\left[p>0.1 ; R^{2}=0.05\right.$, with data for $\geq 9 \mathrm{~d}$ from Allen et al. (2003) ], suggesting that depression requires at least $3 \mathrm{~d}$ to depress this projection and is near maximal at $5 \mathrm{~d}$. The D:Non-D ratio for all cells with at least $5 \mathrm{~d}$ of deprivation was $0.64 \pm 0.05(n=52)$. Thus, deprivation produced a net functional weakening of L4-L2/3 inputs of $\sim 36 \%$.

\section{Whisker deprivation increased paired-pulse ratios}

To determine whether the reduction in L4-L2/3 input-output curves reflected weakening of L4-L2/3 synapses, we measured several physiological properties of L4-L2/3 synapses in rats deprived of the D row of whiskers for 6-9 d, starting at P12, and in sham-deprived littermates (age at recording, P18-P21). We first examined PPR of AMPA receptor-mediated EPSCs, which is clas- sically thought to be inversely correlated with release probability $\left(P_{\mathrm{R}}\right)$ at glutamatergic terminals (Dobrunz and Stevens, 1997; Zucker and Regehr, 2002). AMPA receptor-mediated EPSCs were pharmacologically isolated by bath application of D-AP5 (50 $\mu \mathrm{M})$ and local BMI (see Materials and Methods), and pairs of EPSCs were evoked with ISIs of 12, 20, 40, and 80 ms (Fig. 2). PPR was defined as the ratio of second to first EPSC amplitude. Stimulation intensity was adjusted in each cell to achieve similar first EPSC amplitude (D columns in sham slices, $126 \pm 7.1 \mathrm{pA}, n=25$ cells; $\mathrm{B}$ columns in sham and deprived slices, $152 \pm 14.5 \mathrm{pA}, n=$ 18; deprived D columns, $131 \pm 8.0 \mathrm{pA}, n=29$; ANOVA, $p>0.2$ ). Recordings were performed blind to the animal's sensory experience.

L4-L2/3 synapses in slices from sham-deprived rats showed modest paired pulse depression. PPR was $0.92 \pm 0.06$ at $12 \mathrm{~ms}$ ISI ( $n=19$ in both B and D columns), $0.94 \pm 0.04$ at $20 \mathrm{~ms} \mathrm{ISI}(n=$ $21), 0.95 \pm 0.03$ at $40 \mathrm{~ms}$ ISI $(n=34)$, and $0.88 \pm 0.03$ at $80 \mathrm{~ms}$ ISI ( $n=33$ cells; significantly $<1.0$ only for 80 ms ISI; $t$ test, $p<$ $0.0001)$. This slight paired pulse depression is consistent with recordings at unitary L4-L2/3 connections (Feldmeyer et al., 2002). PPR was identical in B and D columns in sham-deprived rats (Fig. $2 A$, Table 1 ).

PPR was markedly elevated in deprived D columns from whisker-deprived rats, compared with sham-deprived littermates (Fig. 2A, Table 1). For example, at $40 \mathrm{~ms}$ ISI, PPR in deprived D columns was $1.52 \pm 0.10(n=29$ cells $)$ versus $0.96 \pm 0.02(n=$ $25)$ in D columns from sham slices. A similar significant increase was observed for all ISIs (ANOVA; $p<0.0001$ ) (Table 1). PPR in deprived D columns was also significantly greater than in spared B columns from the same slices (Table 1, "matched" data) (ANOVA; $p<0.0001$ ). Thus, whisker deprivation selectively increased PPR within deprived D columns but did not affect PPR in a nearby spared column.

To confirm that PPR correlated with $P_{\mathrm{R}}$ at L4-L2/3 synapses, we experimentally reduced $P_{\mathrm{R}}$ by lowering extracellular calcium from 2.5 to $1.25 \mathrm{~mm}$ (Zucker and Regehr, 2002). As expected, this manipulation significantly increased PPR (ANOVA; $p<0.0001$ ) (Fig. 2 B, Table 1). For example, PPR at $40 \mathrm{~ms}$ ISI was $1.87 \pm 0.09$ $(n=20)$ in low calcium versus $0.93 \pm 0.08(n=10)$ in normal calcium (all recordings in D column). An alternative, nonpresynaptic mechanism for PPR is postsynaptic AMPA receptor desensitization (Otis et al., 1996). To test whether this mechanism contributed to PPR at L4-L2/3 synapses, we applied the AMPA receptor desensitization blocker cyclothiazide (CTZ; 50 $\mu \mathrm{M})$. CTZ increased AMPA current amplitude and duration, consistent with blocking receptor desensitization, but did not alter PPR at any ISI (Fig. 2C, Table 1). These results suggest that PPR primarily reflects $P_{\mathrm{R}}$ at L4-L2/3 synapses, and therefore deprivation weakens these synapses by lowering $P_{\mathrm{R}}$.

\section{Whisker deprivation decreased release probability measured by MK-801}

We measured $P_{\mathrm{R}}$ more directly using a standard assay, the rate of blockade of NMDAR-mediated EPSCs (NMDA-EPSCs) by the irreversible, open-channel blocker MK-801 (Hessler et al., 1993; Rosenmund et al., 1993). Presynaptic stimulation in the presence of extracellular MK-801 causes NMDAR blockade only at synapses that release a vesicle. Because MK-801 is an irreversible blocker, repetitive presynaptic stimulation leads to progressive blockade of NMDA-EPSCs. The time constant of this progressive blockade is inversely related to $P_{\mathrm{R}}$, the probability of action potential propagation to the synapse $\left(P_{\mathrm{f}}\right)$, and the fractional block of 
A Sham Deprived
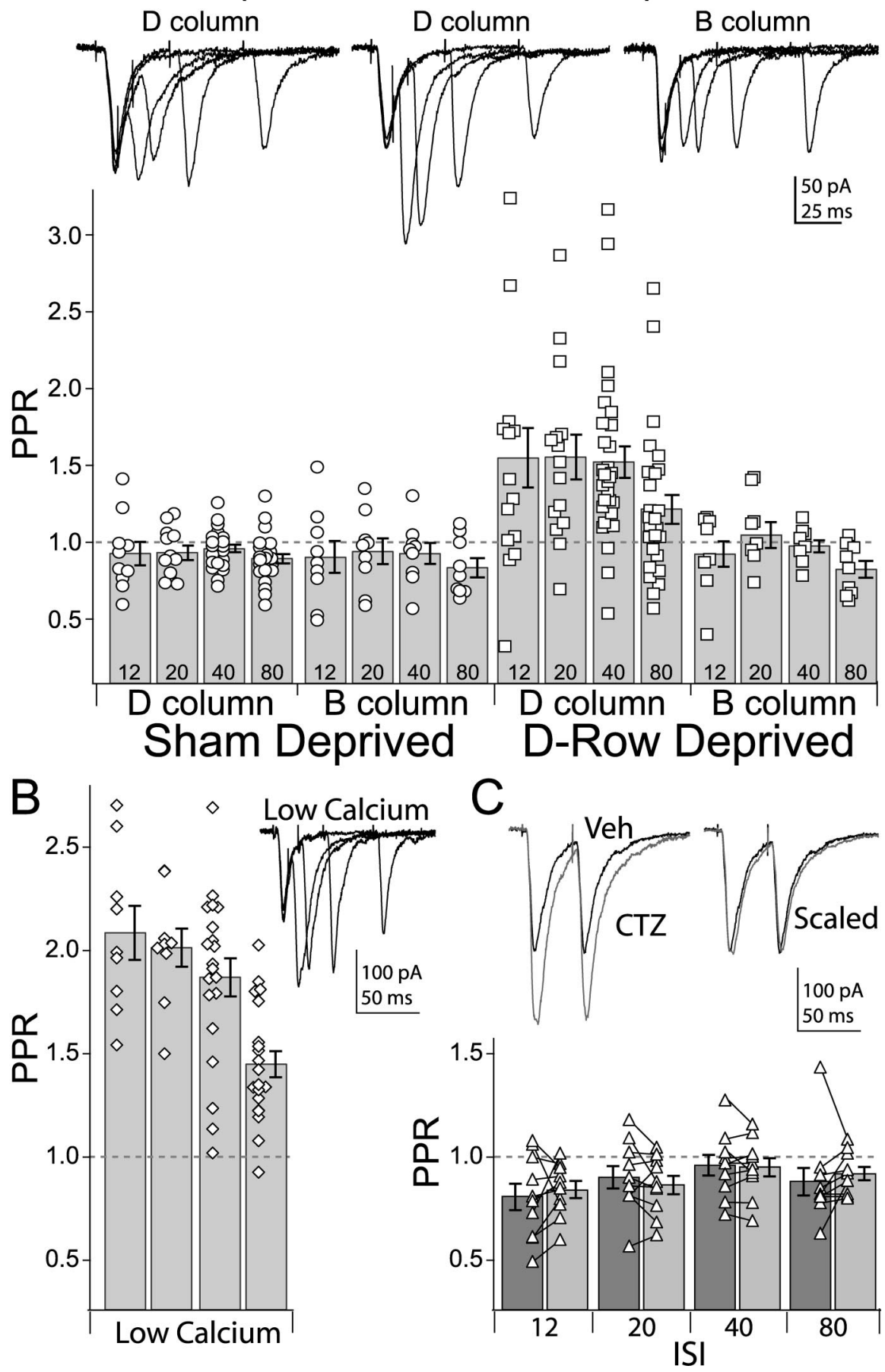

Figure 2. Whisker deprivation increases PPR. $\boldsymbol{A}$, Top, Representative recordings of pairs of AMPA receptor-mediated EPSCS (recorded at $-70 \mathrm{mV}$ ) at ISIs of 12,20,40, and $80 \mathrm{~ms}$ in D and B columns in slices from control and D-row-deprived rats. Bottom, Summary of deprivation effects on PPR. Numbers indicate ISI. $\boldsymbol{B}$, Lowering external calcium from 2.5 to 1.25 mm increases PPR. $\boldsymbol{C}$, CTZ does not alter PPR. Veh, DMSO vehicle control. Error bars are SEM.

open NMDARs by MK-801 during each channel opening (FB) (Hessler et al., 1993; Rosenmund et al., 1993).

We measured the rate of progressive MK-801 blockade of NMDA-EPSCs in slices from rats deprived of D-row whiskers for 6-9 d starting at P12 and from sham-deprived littermates. Recordings were performed blind to deprivation history. NMDAEPSCs were isolated with DNQX $(10 \mu \mathrm{M})$ and either BMI or picrotoxin $(100 \mu \mathrm{M})$ and measured at a $+40 \mathrm{mV}$ holding poten- tial. NMDA-EPSC amplitude was set at $\sim 100 \mathrm{pA}$ in all experiments (sham, $107.0 \pm 8.7 \mathrm{pA}, n=10$; deprived, $116.4 \pm$ $7.2 \mathrm{pA}, n=10$; $p=0.4)$. After a stable baseline, MK-801 (5 $\mu \mathrm{M})$ was added to the perfusate, and stimulation was paused for 10 min to allow MK-801 to equilibrate in the slice. When stimulation resumed, progressive blockade of the NMDA-EPSC was observed (Fig. 3A). Consistent with openchannel blockade and a constant concentration of MK-801, decay kinetics of individual NMDA-EPSCs was sped compared with the predrug condition but subsequently remained constant while MK-801 was present (104-150 sweeps) (Fig. 3A) (Hestrin et al., 1990; Jahr, 1992). The progressive blockade of NMDA-EPSCs was well fit with a double exponential (Fig. 3B) (Hessler et al., 1993; Rosenmund et al., 1993).

MK-801 blockade was slower in deprived D columns than in D columns from sham-deprived littermates (Fig. 3B). The fast time constant of decay $\left(\tau_{\mathrm{f}}\right)$ was twofold slower with deprivation (sham, $5.9 \pm$ 1.0 stimuli, $n=10$; deprived, $11.9 \pm 1.3$, $n=10 ; p<0.005$ ) (Fig. 3D), whereas the slow time constant $\left(\tau_{\mathrm{s}}\right)$ was unchanged (sham, $61.2 \pm 9.6$ stimuli; deprived, $86.5 \pm 15.5 ; p=0.2$ ). The relative amplitude of the slow exponential component $\left(a_{s}\right)$ was similar in deprived $(0.41 \pm 0.05$; $n=10)$ and sham-deprived columns $(0.55 \pm 0.06, n=10 ; p>0.05)$. Slower MK-801 blockade was also observed in deprived columns using a model-independent metric, the number of stimuli required to achieve $50 \%$ block of initial EPSC amplitude (sham, $13.0 \pm 1.8$ stimuli, deprived, $18.2 \pm 1.7 ; p<0.05$ ) (Fig. $3 E)$. These data suggest that $P_{\mathrm{R}}$ was reduced by deprivation (Kaneko and Takahashi, 2004; Nosyreva and Huber, 2005).

To confirm that the rate of MK-801 blockade tracks $P_{\mathrm{R}}$ under our conditions, we measured MK-801 blockade in 1.25 mM calcium (Fig. 3C). Results were compared with standard $2.5 \mathrm{~mm}$ calcium experiments (from sham-deprived experiments shown in Fig. 3B). In low calcium, the fast time constant $\left(\tau_{\mathrm{f}}\right)$ of decay was significantly slower $(15.1 \pm 1.4$ stimuli; $n=9)$ than in $2.5 \mathrm{~mm}$ calcium ( $p<$ $0.0001)$, but the slow time constant $\left(\tau_{\mathrm{s}}, 81.7 \pm 15.8\right.$ stimuli; $p=$ $0.3)$ and relative amplitude of the slow component $\left(a_{s}, 0.44 \pm\right.$ $0.07 ; p=0.3$ ) were unchanged (Fig. $3 D$ ). Correspondingly, the number of stimuli required to achieve $50 \%$ block was greater in low-calcium Ringer's solution ( $18.4 \pm 1.7$ stimuli; $p<0.05$ vs 2.5 mM calcium) (Fig. 3E). These results confirm that MK-801 blockade tracks $P_{\mathrm{R}}$ and demonstrate that the effect of deprivation can be mimicked by lowering calcium. 
The rate of MK-801 blockade is also influenced by the fraction of open NMDARs that are blocked by MK-801 during each channel opening (FB) (Hessler et al., 1993). Thus, the slower MK-801 blockade observed with deprivation could reflect a reduction in $\mathrm{FB}$, rather than $P_{\mathrm{R}}$, as could occur if deprivation shortened NMDAR open time or reduced MK-801 affinity for the channel. To test this possibility, we first measured NMDA-EPSC decay kinetics by fitting the EPSC decay with a single exponential (Fig. $3 F, G$ ). EPSC decay time constants were identical for deprived and sham animals, both during the predrug baseline (sham, $143 \pm 8 \mathrm{~ms}$; deprived, $145 \pm 8 ; p>0.8$ ) and in the presence of MK-801 (sham, $120 \pm 9 \mathrm{~ms}$; deprived, $113 \pm 5 ; p>0.5$ ), indicating that deprivation did not change NMDAR open time. Next, we measured how much MK801 sped NMDA-EPSC decay kinetics within individual cells. The faster EPSC decay in MK-801, relative to baseline, is caused by MK-801 entering and binding to naive NMDARs during channel opening (Huettner and Bean, 1988; Huang and Stevens, 1997) and is a direct reflection of FB (Huang and Stevens, 1997). MK-801 shortened the decay time constant of NMDA-EPSCs similarly in sham and deprived animals (sham, MK-801 caused a $16.6 \pm 3.9 \%$ reduction in decay time constant, relative to baseline; deprived, $21.4 \pm$ $2.7 \%, p=0.3$ ). Thus, $\mathrm{FB}$ is unaffected by deprivation. These data suggest that the slowing of progressive MK-801 blockade by deprivation is caused by a reduction of $P_{\mathrm{R}}$ at $\mathrm{L} 4-\mathrm{L} 2 / 3$ synapses in deprived columns.

\section{Deprivation did not affect mEPSCs}

To determine whether whisker deprivation altered postsynaptic responsiveness to neurotransmitter, we first examined mEPSCs, which represent responses to single, spontaneously released vesicles (Fatt and Katz, 1952; Burgard and Hablitz, 1993). AMPA receptor-mediated mEPSCs (Fig. $4 A$ ) were measured in voltage-clamp recordings from L $2 / 3$ pyramidal cells in the presence of $0.5 \mu \mathrm{M}$ tetrodotoxin, 50 $\mu \mathrm{M}$ D-AP5, and $100 \mu \mathrm{M}$ picrotoxin. Recordings were made in the deprived D column and spared B column of slices from rats deprived of D-row whiskers for 11-13 $\mathrm{d}$ starting at P12. mEPSC identification and analysis were performed blind to sensory experience.

Deprivation did not affect mEPSC amplitude (D, $8.59 \pm 0.36$ $\mathrm{pA} ; \mathrm{B}, 8.30 \pm 0.42 \mathrm{pA} ; n=6$ each; $p=0.6$ ), decay kinetics (decay time constant from single-exponential fit: D, $4.4 \pm 0.2 \mathrm{~ms}$; B, $4.6 \pm 0.1 \mathrm{~ms} ; p=0.4)$, or frequency $(\mathrm{D}, 2.78 \pm 0.37 \mathrm{~Hz} ; \mathrm{B}, 3.06 \pm$ $0.54 \mathrm{~Hz} ; p=0.7)($ Fig. $4 B, C)$. Input resistance $(\mathrm{D}, 244 \pm 7 \mathrm{M} \Omega$; control (nondeprived) rats.
Table 1. Effects of deprivation on PPR at L4 to L2/3 synapses

\begin{tabular}{lllll}
\hline SI (ms) & 12 & 20 & 40 & 80 \\
\hline $\begin{array}{l}\text { Sham-deprived rats } \\
\text { B column }\end{array}$ & $0.91 \pm 0.10(9)$ & $0.94 \pm 0.08(9)$ & $0.93 \pm 0.07(9)$ & $0.83 \pm 0.06(9)$ \\
$\quad$ column & $0.93 \pm 0.08(10)$ & $0.93 \pm 0.05(12)$ & $0.96 \pm 0.02(25)$ & $0.89 \pm 0.03(24)$ \\
D-row-deprived rats & & & \\
B column matched & $0.92 \pm 0.08(9)$ & $1.05 \pm 0.08(9)$ & $0.97 \pm 0.04(9)$ & $0.82 \pm 0.06(9)$ \\
D column $^{\text {matched }}$ & $1.55 \pm 0.19(15)^{\ddagger}$ & $1.55 \pm 0.15(15)^{\ddagger}$ & $1.50 \pm 0.15(15)^{\ddagger}$ & $1.24 \pm 0.15(15)^{\ddagger}$ \\
D column $^{\text {all }}$ & $1.55 \pm 0.19(15)^{*}$ & $1.55 \pm 0.15(15)^{\#}$ & $1.52 \pm 0.10(29)^{\#}$ & $1.21 \pm 0.09(27)^{*}$ \\
Low calcium $^{\text {cll }}$ & $2.09 \pm 0.13(9)^{\#}$ & $2.01 \pm 0.09(9)^{\#}$ & $1.87 \pm 0.09(20)^{\#}$ & $1.45 \pm 0.06(20)^{\#}$ \\
DMSO vehicle $^{\text {ctl }}$ & $0.81 \pm 0.05(10)$ & $0.90 \pm 0.06(10)$ & $0.96 \pm 0.05(10)$ & $0.88 \pm 0.07(10)$ \\
Cyclothiazide $^{\text {ctl }}$ & $0.84 \pm 0.04(10)$ & $0.86 \pm 0.04(10)$ & $0.95 \pm 0.04(10)$ & $0.92 \pm 0.03(10)$ \\
\hline
\end{tabular}

Parentheses indicate number of cells.

${ }^{\ddagger} p<0.05$ versus corresponding IS I in B row in deprived slices, Fisher's PLSD.

${ }^{*} p<0.05$ and ${ }^{*} p<0.001$ versus corresponding IS in D row of sham-deprived slices, Fisher's PLSD.

${ }^{\text {matched }} B$ and $D$ column data recorded in the same slices; ${ }^{\text {all }}$ includes additional slices in which only $D$ column data were recorded; ${ }^{\text {ct }}$ experiments performed in
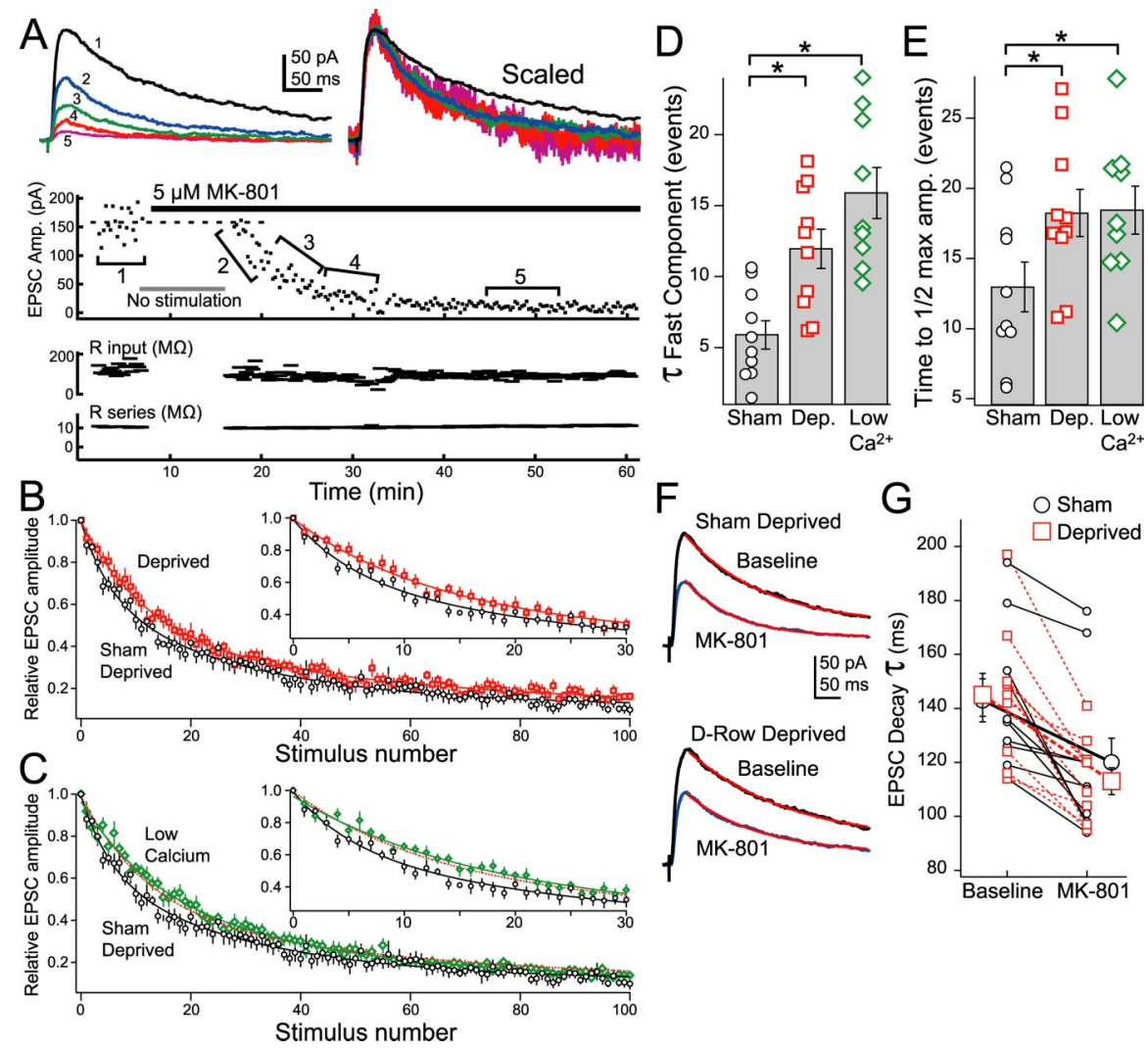

Figure 3. Whisker deprivation slows NMDA-EPSC block by MK-801.A, Example of MK-801-mediated block of transmission. Top left, Averaged NMDAR-mediated EPSC (recorded at $+40 \mathrm{mV}$ ) in baseline conditions (1) and during MK-801 application (2-5). Top right, EPSCs (2-5) scaled to peak amplitude of 1. Bottom, Individual experiment showing peak EPSC amplitude for each stimulus. $B$, Average decay in EPSC amplitude for deprived and sham-deprived conditions. Decays are normalized to the amplitude of the first EPSC in MK-801 and fit to double exponentials. C, EPSC decay for sham-deprived and low-calcium conditions. Dashed line, Fit for deprived condition. Error bars are SEM. B, C, Insets, Expansion of stimulus $0-30$. D, Time constant for fast component of double exponential decay. $\boldsymbol{E}$, Time to reach half-maximal EPSC amplitude. Asterisks indicate $p<0.05$. $\boldsymbol{F}$, NMDA-EPSCs before (black) and immediately after (blue) the addition of MK-801, recorded in sham and deprived columns. Red, Single exponential fit of EPSC decay. G, EPSC decay time constant in the absence and presence of MK-801 for sham-deprived (circles) and deprived (squares) conditions. Error bars are SEM.

$\mathrm{B}, 244 \pm 18 \mathrm{M} \Omega ; p=0.5)$, series resistance $(\mathrm{D}, 13 \pm 3 \mathrm{M} \Omega$; $\mathrm{B}$, $13 \pm 2 \mathrm{M} \Omega ; p=0.9)$, and resting membrane potential $(\mathrm{D},-72 \pm$ $0.5 \mathrm{mV} ; \mathrm{B},-71 \pm 0.5 \mathrm{mV} ; p=0.5)$ were also identical between deprived and spared columns. Thus, whisker deprivation does not alter the average quantal response of synapses onto L2/3 pyramidal neurons. 


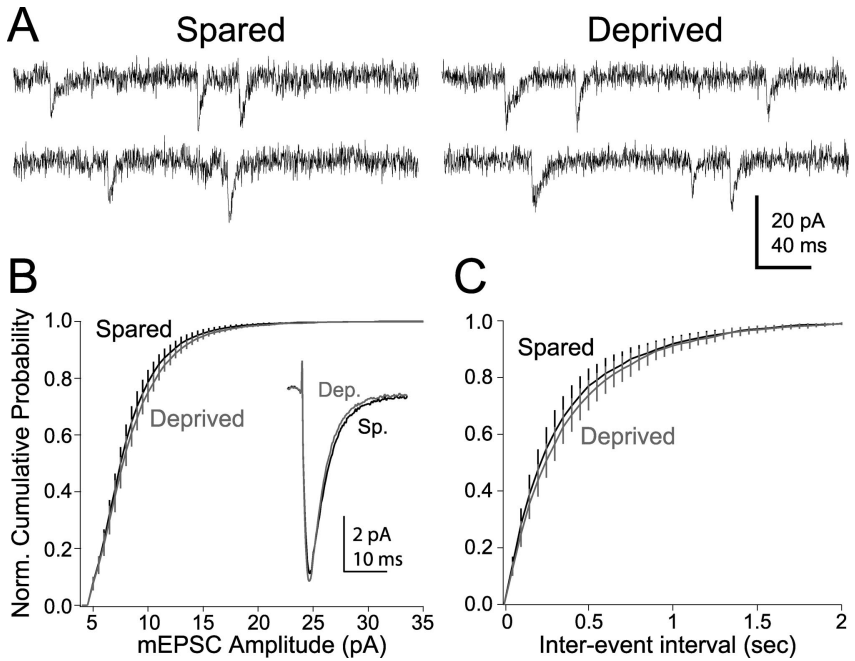

Figure 4. Miniature EPSCS in L2/3 pyramidal cells. $\boldsymbol{A}$, Representative recordings (at -70 $\mathrm{mV}$ ) from L2/3 pyramidal neurons in spared (left) and deprived (right) columns. $\boldsymbol{B}$, Normalized (Norm.) cumulative probability histogram for mEPSC amplitude. Inset, Average mEPSC in deprived and control conditions. C, Normalized cumulative probability histogram for mEPSC interevent interval. Error bars are SEM.

\section{Deprivation did not alter quantal amplitude at L4-L2/3 synapses}

To examine quantal responses at L4-L2/3 synapses selectively, we replaced extracellular calcium with strontium, which suppresses synchronous vesicle release and enhances prolonged, asynchronous release from stimulated terminals. In strontium, evoked EPSCs consist of discrete, temporally dispersed mEPSC-like events (termed SrEPSCs) that represent responses to single, asynchronously released vesicles from stimulated afferents (Miledi and Slater, 1966; Dodge et al., 1969; Goda and Stevens, 1994; Oliet et al., 1996). Thus, by stimulating L4 in strontium, we could measure quantal amplitude at L4-L2/3 synapses in relative isolation from other inputs.

We recorded SrEPSCs in L2/3 pyramidal cells in response to extracellular stimulation in L4. Recordings were made in deprived (D) and spared (non-D; usually B) columns of slices from rats with D-row whiskers deprived for 7-12 d, beginning at P12. Data analysis was performed blind to column identity. Replacing calcium with strontium decreased peak EPSC amplitude, consistent with a decrease in synchronous transmitter release, and led to a large number of small asynchronous EPSCs (Fig. 5A). SrEPSCs were similar to mEPSCs in amplitude and kinetics and had primarily constant amplitude over the $\sim 350$ ms after stimulation, consistent with the hypothesis that SrEPSCs represent quantal responses to individual, asynchronously released vesicles of transmitter (Fig. $5 A, B, D$ ).

SrEPSC amplitude was identical in deprived and spared columns (deprived, $8.63 \pm 0.18 \mathrm{pA}, n=13$; spared, $8.61 \pm 0.17, n=$ $16 ; p=0.9$ ). Decay time constant was also identical (decay time constant from single exponential fit: $\mathrm{D}, 3.9 \pm 0.2 \mathrm{~ms} ; \mathrm{B}, 3.9 \pm 0.2$ $\mathrm{ms} ; p=0.9$ ) (Fig. $5 C$ ). Thus, deprivation does not alter quantal amplitude or quantal response kinetics at L4-L2/3 synapses.

\section{Deprivation did not alter AMPA to NMDA current ratio}

We also examined the ratio of AMPA to NMDA receptormediated currents (AMPA:NMDA ratio), which is often altered by postsynaptic forms of plasticity that differentially regulate AMPA and NMDA receptor function (Crair and Malenka, 1995; Carroll et al., 2001). AMPA:NMDA ratio is not expected to be altered by changes in presynaptic function, which should affect AMPA and NMDA receptor-mediated currents similarly. We measured AMPA and NMDA receptor-mediated currents in voltage clamp in D-row-deprived and sham-deprived rats (P18P20; deprivation began at P12). Voltage-clamp recordings were made from L2/3 neurons in D and B barrel columns, blind to sensory experience. AMPA:NMDA ratio was operationally defined as the peak current amplitude, at a holding potential of -80 $\mathrm{mV}$ (presumed AMPA current), divided by the current at +40 $\mathrm{mV}$ measured $100 \mathrm{~ms}$ from EPSC onset (presumed NMDA current). D-AP5 $(50 \mu \mathrm{M})$ blocked $87.8 \pm 2.6 \%$ of current at $+40 \mathrm{mV}$ at this time point, indicating that it represents primarily NMDA current $(n=6)$ (Fig. $6 A)$.

In sham-deprived rats, AMPA:NMDA ratios were similar across barrel columns ( $\mathrm{D}$ column, $0.86 \pm 0.12, n=10$; B column, $0.83 \pm 0.12, n=7 ; p=0.8$ ) (Fig. $6 B$ ). In recordings from $\mathrm{D}$-rowdeprived rats, AMPA:NMDA ratios in deprived D columns $(0.96 \pm 0.14 ; n=12)$ were identical to spared B columns $(0.94 \pm$ $0.12 ; n=10 ; p=0.9)$ and not significantly different from recordings from sham-deprived rats $(p=0.6)$. These results indicate that deprivation does not alter the relative functional expression of postsynaptic AMPA and NMDA receptors.

\section{Deprivation-induced synaptic weakening was not simply a failure of development}

The period of whisker deprivation studied above (P12 to P18P21) overlaps with a period of active development for L4-L2/3 synapses. Extensive synaptogenesis and axonal and dendritic elaboration occur through the second postnatal week (Micheva and Beaulieu, 1996; De Felipe et al., 1997; Bender et al., 2003), and the magnitude of whisker-evoked postsynaptic potentials and spiking responses increase until $\sim$ P20 (Stern et al., 2001). Thus, whisker deprivation may lead to synaptic weakening either by actively reducing synaptic strength at existing L4-L2/3 synapses or by impairing their normal development. To differentiate these possibilities, we tested whether whisker deprivation beginning at P20, when L4-L2/3 synapses are more mature, produced the same magnitude and time course of weakening of L4-L2/3 inputs as deprivation that began at P12.

Whiskers were plucked for 4-6 d (mean, $4.7 \mathrm{~d}$ ), starting at P20, and input-output curves for subthreshold responses were obtained from deprived (D) and spared (non-D) columns using the same techniques as above. We found that input-output curves for cells in deprived columns were significantly smaller than those in spared columns of the same slice $(p<0.005$, ANOVA; D column, $n=20$ cells; non-D, $n=16,10$ slices from six rats; $p<0.05$ at $1.3-1.5 \times$, PLSD) (Fig. $7 A$ ). Moreover, the D:Non-D EPSP ratio in rats deprived for $4-6 \mathrm{~d}$ beginning at P20 $(0.78 \pm 0.10 ; n=20$ cells $)$ was not significantly different from that observed after $5 \mathrm{~d}$ of deprivation from P12 [0.72 $\pm 0.11 ; n=$ 15 cells; $p>0.6$ (data from Fig. $1 E$ )] (Fig. $7 B$ ). There was no correlation between D:Non-D EPSP ratio and plucking duration within the $4-6 \mathrm{~d}$ range $\left(p=0.9 ; R^{2}<0.001\right)$.

To determine whether the time course of deprivation-induced depression was similar between young (P12) and more mature (P20) rats, we deprived rats for just $2 \mathrm{~d}$ beginning at P20. This brief deprivation did not alter input-output curves in deprived columns relative to spared columns ( $p=0.9$, ANOVA; D column, $n=10$ cells; non-D, $n=10$, five slices from four rats) (Fig. $7 A$ ). Correspondingly, the D:Non-D EPSP ratio was not different from age-matched control rats [ $2 \mathrm{~d}$ deprived, $1.13 \pm 0.16, n=10$ D column cells; control (P21-P25), $1.09 \pm 0.14, n=11 \mathrm{D}$ column cells; $p=0.8$ ] (Fig. $7 B$ ). Thus, $2 \mathrm{~d}$ of deprivation was insuf- 
ficient to drive whisker deprivationinduced depression at P20. These results indicate that the magnitude and time course of deprivation-induced synaptic depression are similar at P12 and P20 (Fig. $7 B$ ) and are consistent with the hypothesis that whisker deprivation weakens existing synapses rather than impairing development of immature synapses.

\section{Discussion}

These results show that whisker deprivation weakens L4-L2/3 synapses. Deprivation increased PPR and slowed MK-801 blockade of NMDA-EPSCs, consistent with a deprivation-induced decrease in presynaptic release probability. Deprivation did not alter mEPSC or SrEPSC amplitude, indicating that the postsynaptic response to individual vesicles of transmitter (quantal amplitude) was unaltered. Thus, deprivation appears to presynaptically weaken L4-L2/3 synapses.

\section{Time course and magnitude of} deprivation-induced weakening of L4-L2/3 inputs

Significant depression of L4-L2/3 inputs required at least $4 \mathrm{~d}$ of deprivation (Fig. 1). This is consistent with the relatively slow time course for deprivation-induced weakening of extracellular spiking responses to the deprived whisker in vivo (Fox, 1992; Glazewski and Fox, 1996). This further supports the hypothesis that weakening of L4-L2/3 synapses may mediate depression of deprived whisker responses in vivo (Allen et al., 2003; Shepherd et al., 2003).

Whisker deprivation produced a mean $36 \%$ decrease in L4-L2/3 EPSPs in deprived S1 columns, based on analysis of input-output curve amplitudes. Inputoutput curves were unaltered in spared columns (Allen et al., 2003). This decrease in L4-L2/3 EPSPs in deprived columns is smaller than the $50-70 \%$ reduction in spiking responses to deprived whiskers that has been measured in vivo after whisker deprivation (Glazewski and Fox, 1996; Foeller et al., 2005). Thus, weakening of L4-L2/3 excitatory inputs is a major, but not sole, mechanism underlying loss of deprived whisker responses in vivo. Other mechanisms may include alterations in cortical inhibition, amplification of plasticity by spike threshold, or weakening of other excitatory inputs to L2/3 neurons (Foeller and Feldman, 2004; Foeller et al., 2005).

Evidence that deprivation reduces release probability Deprivation selectively increased PPR in deprived barrel columns (Fig. 2), suggesting that presynaptic release probability was decreased (Zucker and Regehr, 2002). PPR appeared to track presynaptic, rather than postsynaptic, function at L4-L2/3 synapses, because it varied inversely with calcium concentration and was unaltered by blocking AMPA receptor desensitization. In addi- tion, analysis of AMPA:NMDA ratios indicated that deprivation did not increase the proportion of "silent," NMDAR-only synapses (Fig. 6), which is another postsynaptic means of altering PPR (Poncer and Malinow, 2001). Thus, the increased PPR in deprived columns appears likely to reflect a deprivation-induced decrease in $P_{\mathrm{R}}$ at L4-L2/3 synapses.

Deprivation-induced changes in PPR were not observed at L4-L2/3 synapses in deprived columns in a previous study in which multiple rows of whiskers, rather than a single row, were deprived (Finnerty et al., 1999). This suggests that deprivationinduced presynaptic weakening is sensitive to the specific pattern of whisker use and may be driven most strongly by competition between neighboring active and deprived columns (Glazewski et al., 1998; Allen et al., 2003).

Deprivation also slowed the progressive blockade of NMDAEPSCs by MK-801, also indicating that $P_{\mathrm{R}}$ was reduced in deprived columns (Fig. 3). The rate of blockade by MK- 801 is in- 


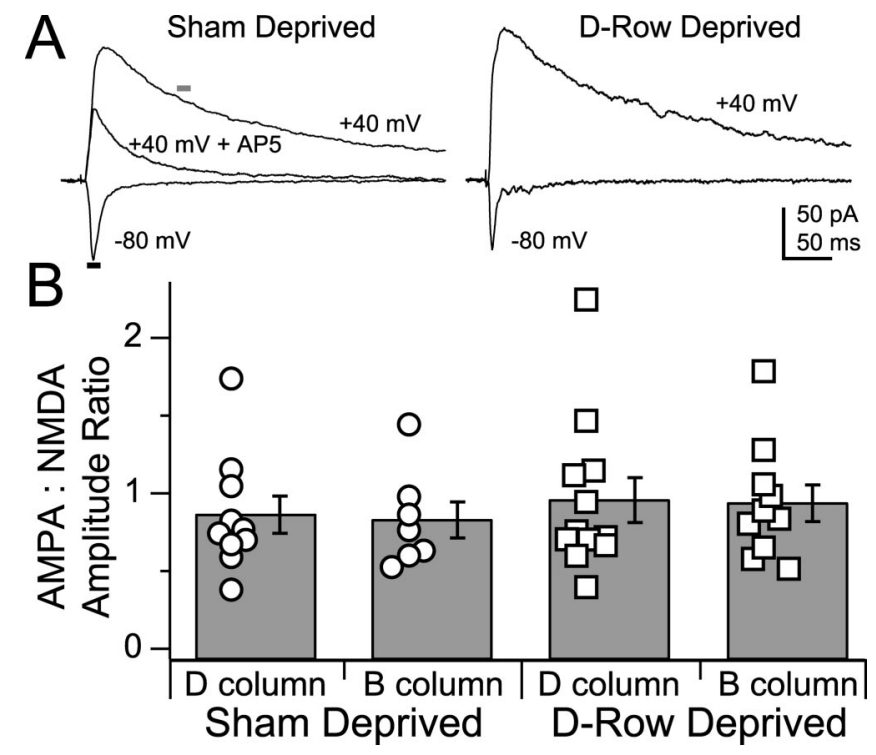

Figure 6. AMPA:NMDA ratio at L4-L2/3 synapses. A, Method for measuring AMPA:NMDA ratio. Traces show mean EPSCs from single representative cells at -80 and $+40 \mathrm{mV}$. The AMPA:NMDA ratio was defined as peak current at $-80 \mathrm{mV}$ (AMPA current; black bar) divided by current at $+40 \mathrm{mV}, 100 \mathrm{~ms}$ from EPSC onset (NMDA current; gray bar). $\boldsymbol{B}$, Summary of AMPA: NMDA ratios in deprived and sham-deprived conditions. Error bars are SEM.
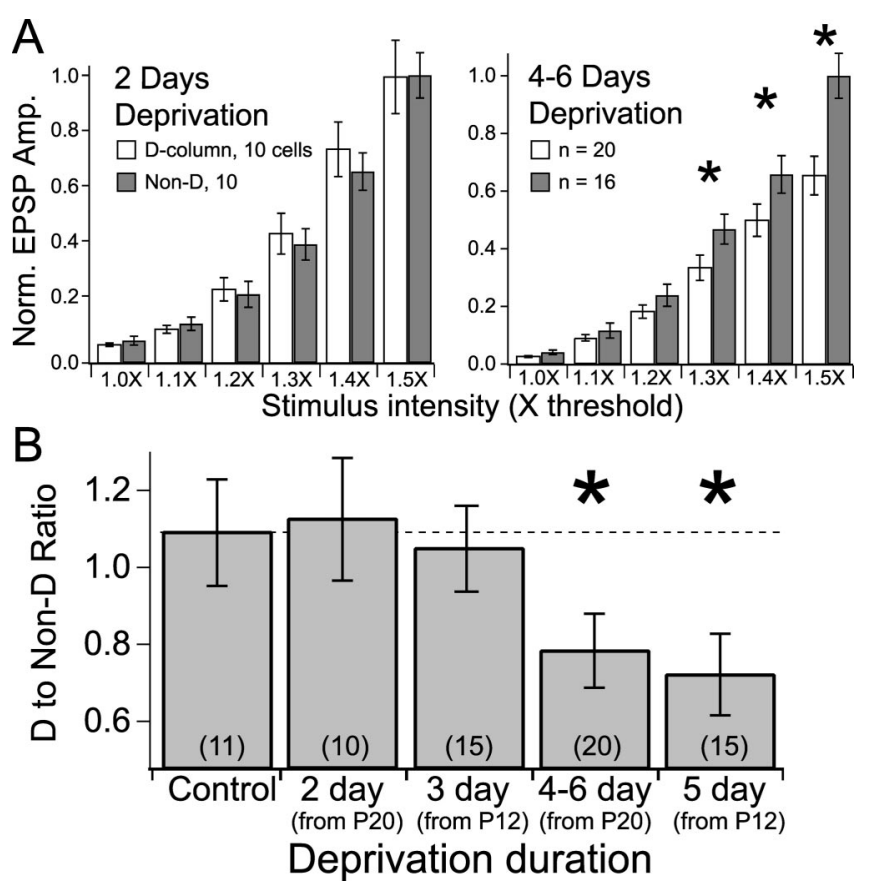

Figure 7. Time course for deprivation-induced depression in more mature animals. $\boldsymbol{A}$, Normalized (Norm.) input- output curves after 2 and $4-6 \mathrm{~d}$ of whisker deprivation beginning at P20. Data are normalized to mean EPSP amplitude (Amp.) for cells in spared column at 1.5 times threshold. The asterisk indicates deprived condition significantly different from spared. $\boldsymbol{B}, \mathrm{Mag}$ nitude of deprivation-induced depression of input-output curves as calculated by D:Non-D ratio. Error bars are SEM.

versely proportional to the quantity $\left(P_{\mathrm{R}} \times P_{\mathrm{f}} \times \mathrm{FB}\right)$, where $P_{\mathrm{R}}$ is release probability, $P_{\mathrm{f}}$ is probability of AP propagation to the synapse, and FB is the fraction of open NMDA receptors that are blocked by MK-801 during each channel opening (Hessler et al., 1993; Rosenmund et al., 1993). Deprivation from P12 did not alter the decay time of individual NMDA-EPSCs or the speeding of this decay by MK-801, which is a robust measure of FB (Huettner and Bean, 1988; Huang and Stevens, 1997). Thus, deprivation must decrease the quantity $\left(P_{\mathrm{R}} \times P_{\mathrm{f}}\right)$, which reflects the probability of vesicle release after a single action potential in the presynaptic soma. Because deprivation also increases PPR, the simplest hypothesis is that deprivation specifically decreases $P_{\mathrm{R}}$ (Zucker and Regehr, 2002), although changes in $P_{\mathrm{f}}$ cannot be ruled out (Debanne et al., 1997).

The progressive blockade of NMDA-EPSCs by MK-801 often follows a double exponential time course, which may reflect either the existence of separate populations of high- $P_{\mathrm{R}}$ and low $-P_{\mathrm{R}}$ synapses (Hessler et al., 1993; Rosenmund et al., 1993) or a continuous distribution of $P_{\mathrm{R}}$ (Huang and Stevens, 1997). Our finding that deprivation caused a twofold increase in $\tau_{\mathrm{f}}$ suggests that deprivation caused a $50 \%$ decrease in $P_{\mathrm{R}}$ at high- $P_{\mathrm{R}}$ synapses (whether a distinct class or simply one end of a $P_{\mathrm{R}}$ continuum), with less or no effect on low- $P_{\mathrm{R}}$ synapses. Other forms of plasticity, including metabotropic glutamate receptor-dependent LTD, have also been shown to preferentially affect high- $P_{\mathrm{R}}$ synapses (Kaneko and Takahashi, 2004; Nosyreva and Huber, 2005).

\section{Deprivation does not affect postsynaptic function}

No changes in postsynaptic function were observed in deprived columns, as assessed by the amplitude of mEPSCs and SrEPSCs, which selectively reflect responses at L4-L2/3 synapses. Thus, postsynaptic quantal amplitude was unchanged. Previous studies showed, similarly, that postsynaptic excitability was unchanged or only modestly changed by whisker deprivation (Allen et al., 2003; Maravall et al., 2004). We did not observe a change in mEPSC frequency with whisker deprivation, as might be expected if $P_{\mathrm{R}}$ at L4-L2/3 synapses decreases (Redman, 1990). We hypothesize that changes in $P_{\mathrm{R}}$ at L4-L2/3 inputs may have been diluted or masked by the large number of other synaptic inputs to L2/3 cells, the $P_{\mathrm{R}}$ of which does not change, or that homeostatic increases in $P_{\mathrm{R}}$ may have occurred at other synapses, masking the expected decrease in mEPSC frequency.

\section{Does deprivation-induced synaptic weakening represent LTD?}

LTD has long been hypothesized as a mechanism for Hebbian map plasticity, and has been specifically proposed to contribute to the loss of cortical responsiveness to deprived or underused sensory inputs (Stent, 1973; Bear et al., 1987; Fox, 2002; Feldman and Brecht, 2005). Substantial evidence supports this hypothesis. First, deprivation-induced receptive field plasticity is activity and NMDAR dependent, like classical LTD (Garraghty and Muja, 1996; Rema et al., 1998; Rittenhouse et al., 1999). Second, deprivation causes measurable physiological weakening of specific cortical synapses (Allen et al., 2003; Heynen et al., 2003; Shepherd et al., 2003). Third, deprivation-induced synaptic weakening occludes subsequent LTD, suggesting that it may represent LTD induced in vivo (Allen et al., 2003; Heynen et al., 2003). Fourth, in $\mathrm{S} 1$, deprivation acutely reverses the precise, millisecond-scale timing of L4 and L2/3 spikes in a manner that is quantitatively appropriate to drive spike timing-dependent LTD at L4-L2/3 synapses (Celikel et al., 2004). However, experiments testing whether specific forms of LTD are required for cortical map plasticity have produced mixed results (Hensch, 2005): while in some cases, blocking LTD blocks map plasticity (Fischer et al., 2004); in other cases, map plasticity is unimpaired (Hensch and Stryker, 1996; Renger et al., 2002), suggesting that LTD and plasticity are not associated (Yang et al., 2005). Thus, whether deprivation- 
induced synaptic weakening truly represents LTD remains unknown.

A major goal of the present study was to compare the detailed expression mechanisms of deprivation-induced synaptic weakening and LTD at L4-L2/3 synapses to determine whether they were similar. Although LTD appears to be expressed primarily postsynaptically at mature hippocampal synapses (Malinow and Malenka, 2002), several forms of cortical LTD have presynaptic expression mechanisms (Egger et al., 1999; Sjostrom et al., 2003), including spike timing-dependent LTD at L4-L2/3 synapses, which has been specifically implicated in deprivation-induced whisker map plasticity (Feldman, 2000; Celikel et al., 2004; Bender et al., 2006). Thus, deprivation-induced synaptic weakening and LTD are both presynaptically expressed at L4-L2/3 synapses, suggesting they may represent the same process.

Despite this similarity in expression mechanisms, it remains unresolved whether deprivation-induced synaptic weakening actually represents LTD induced in vivo. A viable alternative is that deprivation weakens cortical circuits by synapse removal (perhaps of the highest $P_{\mathrm{R}}$ synapses), rather than synaptic weakening (Chklovskii et al., 2004; Hensch, 2005); however, deprivation does not produce a detectable loss of L4 axonal arbors or boutons at the light level (Bender et al., 2003). Another critical issue is the time course of plasticity. At L4-L2/3 synapses, LTD is commonly expressed within minutes of induction in vitro (CastroAlamancos et al., 1995; Feldman, 2000), and whisker deprivation causes an immediate reversal of the timing of sensory-evoked spikes at L4 and L2/3 neurons in anesthetized animals, which would be predicted to rapidly drive spike timing-dependent LTD at L4-L2/3 synapses (Celikel et al., 2004). Why then are 4-5 d of whisker deprivation required to significantly weaken L4-L2/3 synapses in vivo? One possibility is that in behaving animals, whisker contact-driven spikes are outnumbered by spontaneous spikes or spikes driven by whisker self-motion (Fee et al., 1997), the timing of which may be unaltered by whisker deprivation. As a result, whisker deprivation may produce only a relatively minor change in overall spike timing, leading to a gradual development of spike timing-dependent LTD. Another possibility is that spontaneous network activity counteracts and slows the accrual of LTD in vivo (Xu et al., 1998; Zhou et al., 2003).

\section{Conclusions}

Our results confirm that L4-L2/3 synapses are a major site of plasticity during experience-dependent modification of the S1 whisker map. Whisker deprivation weakens L4-L2/3 synapses in deprived cortical columns, and this weakening is expressed presynaptically, similar to LTD at L4-L2/3 synapses. Whether this LTD-like synaptic weakening causally drives the loss of cortical responses to deprived sensory inputs (Fox, 2002) remains to be determined.

\section{References}

Allen CB, Celikel T, Feldman DE (2003) Long-term depression induced by sensory deprivation during cortical map plasticity in vivo. Nat Neurosci 6:291-299.

Armstrong-James M, Fox K, Das-Gupta A (1992) Flow of excitation within rat barrel cortex on striking a single vibrissa. J Neurophysiol 68:1345-1358.

Bear MF, Cooper LN, Ebner FF (1987) A physiological basis for a theory of synapse modification. Science 237:42-48.

Bender KJ, Rangel J, Feldman DE (2003) Development of columnar topography in the excitatory layer 4 to layer $2 / 3$ projection in rat barrel cortex. J Neurosci 23:8759-8770.

Bender VA, Bender KJ, Braiser DJ, Feldman DE (2006) Two coincidence detectors for spike timing-dependent plasticity in somatosensory cortex. J Neurosci 26:4166-4177.

Buonomano DV, Merzenich MM (1998) Cortical plasticity: from synapses to maps. Annu Rev Neurosci 21:149-186.

Burgard EC, Hablitz JJ (1993) NMDA receptor-mediated components of miniature excitatory synaptic currents in developing rat neocortex. J Neurophysiol 70:1841-1852.

Carroll RC, Beattie EC, von Zastrow M, Malenka RC (2001) Role of AMPA receptor endocytosis in synaptic plasticity. Nat Rev Neurosci 2:315-324.

Castro-Alamancos MA, Donoghue JP, Connors BW (1995) Different forms of synaptic plasticity in somatosensory and motor areas of the neocortex. J Neurosci 15:5324-5333.

Celikel T, Szostak VA, Feldman DE (2004) Modulation of spike timing by sensory deprivation during induction of cortical map plasticity. Nat Neurosci 7:534-541.

Chklovskii DB, Mel BW, Svoboda K (2004) Cortical rewiring and information storage. Nature 431:782-788.

Connors BW, Gutnick MJ (1990) Intrinsic firing patterns of diverse neocortical neurons. Trends Neurosci 13:99-104.

Crair MC, Malenka RC (1995) A critical period for long-term potentiation at thalamocortical synapses. Nature 375:325-328.

Debanne D, Guerineau NC, Gahwiler BH, Thompson SM (1997) Actionpotential propagation gated by an axonal I(A)-like $\mathrm{K}^{+}$conductance in hippocampus. Nature 389:286-289.

De Felipe J, Marco P, Fairen A, Jones EG (1997) Inhibitory synaptogenesis in mouse somatosensory cortex. Cereb Cortex 7:619-634.

Dinse HR, Ragert P, Pleger B, Schwenkreis P, Tegenthoff M (2003) Pharmacological modulation of perceptual learning and associated cortical reorganization. Science 301:91-94.

Dobrunz LE, Stevens CF (1997) Heterogeneity of release probability, facilitation, and depletion at central synapses. Neuron 18:995-1008.

Dodge Jr FA, Miledi R, Rahamimoff R (1969) Strontium and quantal release of transmitter at the neuromuscular junction. J Physiol (Lond) 200:267-283.

Egger V, Feldmeyer D, Sakmann B (1999) Coincidence detection and changes of synaptic efficacy in spiny stellate neurons in rat barrel cortex. Nat Neurosci 2:1098-1105.

Fatt P, Katz B (1952) Spontaneous subthreshold activity at motor nerve endings. J Physiol (Lond) 117:109-128.

Fee MS, Mitra PP, Kleinfeld D (1997) Central versus peripheral determinants of patterned spike activity in rat vibrissa cortex during whisking. J Neurophysiol 78:1144-1149.

Feldman DE (2000) Timing-based LTP and LTD at vertical inputs to layer II/III pyramidal cells in rat barrel cortex. Neuron 27:45-56.

Feldman DE, Brecht M (2005) Map plasticity in somatosensory cortex. Science 310:810-815.

Feldmeyer D, Lubke J, Silver RA, Sakmann B (2002) Synaptic connections between layer 4 spiny neurone-layer $2 / 3$ pyramidal cell pairs in juvenile rat barrel cortex: physiology and anatomy of interlaminar signalling within a cortical column. J Physiol (Lond) 538:803-822.

Finnerty GT, Roberts LS, Connors BW (1999) Sensory experience modifies the short-term dynamics of neocortical synapses. Nature 400:367-371.

Fischer QS, Beaver CJ, Yang Y, Rao Y, Jakobsdottir KB, Storm DR, McKnight GS, Daw NW (2004) Requirement for the RIIbeta isoform of PKA, but not calcium-stimulated adenylyl cyclase, in visual cortical plasticity. J Neurosci 24:9049-9058.

Foeller E, Feldman DE (2004) Synaptic basis for developmental plasticity in somatosensory cortex. Curr Opin Neurobiol 14:89-95.

Foeller E, Celikel T, Feldman DE (2005) Inhibitory sharpening of receptive fields contributes to whisker map plasticity in rat somatosensory cortex. J Neurophysiol 94:4387-4400.

Fox K (1992) A critical period for experience-dependent synaptic plasticity in rat barrel cortex. J Neurosci 12:1826-1838.

Fox K (2002) Anatomical pathways and molecular mechanisms for plasticity in the barrel cortex. Neuroscience 111:799-814.

Garraghty PE, Muja N (1996) NMDA receptors and plasticity in adult primate somatosensory cortex. J Comp Neurol 367:319-326.

Gilbert CD (1998) Adult cortical dynamics. Physiol Rev 78:467-485.

Glazewski S, Fox K (1996) Time course of experience-dependent synaptic potentiation and depression in barrel cortex of adolescent rats. J Neurophysiol 75:1714-1729.

Glazewski S, McKenna M, Jacquin M, Fox K (1998) Experience-dependent 
depression of vibrissae responses in adolescent rat barrel cortex. Eur J Neurosci 10:2107-2116.

Goda Y, Stevens CF (1994) Two components of transmitter release at a central synapse. Proc Natl Acad Sci USA 91:12942-12946.

Hensch TK (2005) Critical period plasticity in local cortical circuits. Nat Rev Neurosci 6:877-888.

Hensch TK, Stryker MP (1996) Ocular dominance plasticity under metabotropic glutamate receptor blockade. Science 272:554-557.

Hessler NA, Shirke AM, Malinow R (1993) The probability of transmitter release at a mammalian central synapse. Nature 366:569-572.

Hestrin S, Sah P, Nicoll RA (1990) Mechanisms generating the time course of dual component excitatory synaptic currents recorded in hippocampal slices. Neuron 5:247-253.

Heynen AJ, Yoon BJ, Liu CH, Chung HJ, Huganir RL, Bear MF (2003) Molecular mechanism for loss of visual cortical responsiveness following brief monocular deprivation. Nat Neurosci 6:854-862.

Huang EP, Stevens CF (1997) Estimating the distribution of synaptic reliabilities. J Neurophysiol 78:2870-2880.

Huettner JE, Bean BP (1988) Block of N-methyl-D-aspartate-activated current by the anticonvulsant MK-801: selective binding to open channels. Proc Natl Acad Sci USA 85:1307-1311.

Jahr CE (1992) High probability opening of NMDA receptor channels by L-glutamate. Science 255:470-472.

Kaneko M, Takahashi T (2004) Presynaptic mechanism underlying cAMPdependent synaptic potentiation. J Neurosci 24:5202-5208.

LeVay S, Wiesel TN, Hubel DH (1980) The development of ocular dominance columns in normal and visually deprived monkeys. J Comp Neurol 191:1-51.

Malinow R, Malenka RC (2002) AMPA receptor trafficking and synaptic plasticity. Annu Rev Neurosci 25:103-126.

Maravall M, Koh IY, Lindquist WB, Svoboda K (2004) Experiencedependent changes in basal dendritic branching of layer $2 / 3$ pyramidal neurons during a critical period for developmental plasticity in rat barrel cortex. Cereb Cortex 14:655-664.

Micheva KD, Beaulieu C (1996) Quantitative aspects of synaptogenesis in the rat barrel field cortex with special reference to GABA circuitry. J Comp Neurol 373:340-354.

Miledi R, Slater CR (1966) The action of calcium on neuronal synapses in the squid. J Physiol (Lond) 184:473-498.

Nosyreva ED, Huber KM (2005) Developmental switch in synaptic mechanisms of hippocampal metabotropic glutamate receptor-dependent longterm depression. J Neurosci 25:2992-3001.

Oliet SH, Malenka RC, Nicoll RA (1996) Bidirectional control of quantal size by synaptic activity in the hippocampus. Science 271:1294-1297.

Otis T, Zhang S, Trussell LO (1996) Direct measurement of AMPA receptor desensitization induced by glutamatergic synaptic transmission. J Neurosci 16:7496-7504.

Poncer JC, Malinow R (2001) Postsynaptic conversion of silent synapses during LTP affects synaptic gain and transmission dynamics. Nat Neurosci 4:989-996.

Redman S (1990) Quantal analysis of synaptic potentials in neurons of the central nervous system. Physiol Rev 70:165-198.

Rema V, Armstrong-James M, Ebner FF (1998) Experience-dependent plasticity of adult rat $\mathrm{S} 1$ cortex requires local NMDA receptor activation. J Neurosci 18:10196-10206.

Renger JJ, Hartman KN, Tsuchimoto Y, Yokoi M, Nakanishi S, Hensch TK (2002) Experience-dependent plasticity without long-term depression by type 2 metabotropic glutamate receptors in developing visual cortex. Proc Natl Acad Sci USA 99:1041-1046.

Rittenhouse CD, Shouval HZ, Paradiso MA, Bear MF (1999) Monocular deprivation induces homosynaptic long-term depression in visual cortex. Nature 397:347-350.

Roberts EB, Meredith MA, Ramoa AS (1998) Suppression of NMDA receptor function using antisense DNA block ocular dominance plasticity while preserving visual responses. J Neurophysiol 80:1021-1032.

Rosenmund C, Clements JD, Westbrook GL (1993) Nonuniform probability of glutamate release at a hippocampal synapse. Science 262:754-757.

Shepherd GM, Pologruto TA, Svoboda K (2003) Circuit analysis of experience-dependent plasticity in the developing rat barrel cortex. Neuron 38:277-289.

Sjostrom PJ, Turrigiano GG, Nelson SB (2003) Neocortical LTD via coincident activation of presynaptic NMDA and cannabinoid receptors. Neuron 39:641-654.

Stent GS (1973) A physiological mechanism for Hebb's postulate of learning. Proc Natl Acad Sci USA 70:997-1001.

Stern EA, Maravall M, Svoboda K (2001) Rapid development and plasticity of layer 2/3 maps in rat barrel cortex in vivo. Neuron 31:305-315.

Xu L, Anwyl R, Rowan MJ (1998) Spatial exploration induces a persistent reversal of long-term potentiation in rat hippocampus. Nature 394:891-894.

Yang Y, Fischer QS, Zhang Y, Baumgartel K, Mansuy IM, Daw NW (2005) Reversible blockade of experience-dependent plasticity by calcineurin in mouse visual cortex. Nat Neurosci 8:791-796.

Yao H, Dan Y (2005) Synaptic learning rules, cortical circuits, and visual function. Neuroscientist 11:206-216.

Zhou Q, Tao HW, Poo MM (2003) Reversal and stabilization of synaptic modifications in a developing visual system. Science 300:1953-1957.

Zucker RS, Regehr WG (2002) Short-term synaptic plasticity. Annu Rev Physiol 64:355-405. 